\title{
Research Paper: Narcissistic Disturbances as the Bedrock of Difficulties in Emotional Regulation and Self-Destructive Behavior in Melancholic Patients: A Psychoanalytic Re-Evaluation of Narcissus Myth
}

\author{
Majid Hosseinabadi ${ }^{1}$, Bahram Ali Ghanbary Hashemabady ${ }^{1^{*}}$, Hossein Kareshki ${ }^{2}$, Morteza Modares Gharavi \\ 1. Department of Psychology, Faculty of Education Sciences and Psychology, Ferdowsi University of Mashhad, Mashhad, Iran. \\ 2. Department of Education, Faculty of Education Sciences and Psychology, Ferdowsi University of Mashhad, Mashhad, Iran.
}

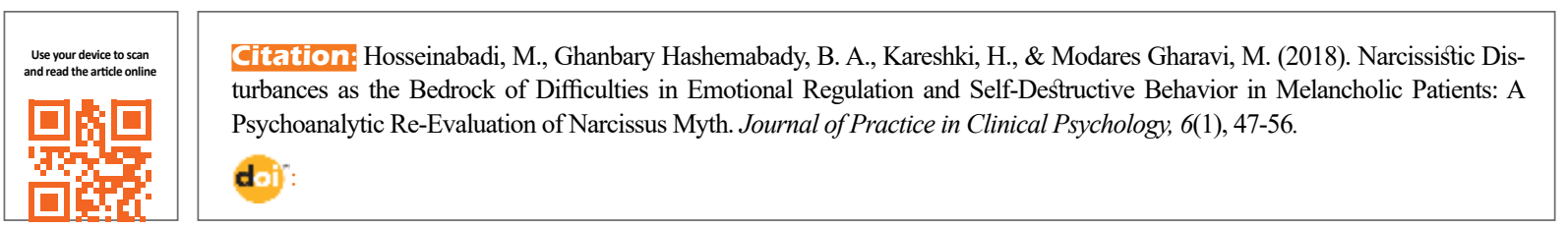

Article info:

Received: 23 Jul. 2017

Accepted: 18 Nov. 2017

\section{Keywords:}

Depression, Narcissism, Emotion, Self-destructive behavior, Psychoanalytic therapy \begin{abstract}
Objective: The association of narcissistic disturbances in patients with melancholia symptoms has been described in various studies. The mechanism by which narcissistic disturbances may contribute to difficulties in emotional regulation and self-destructive behavior in melancholic patients have not been explored well. This lack of attention represents a vital theoretical ambiguity about the interaction of narcissism and death drive, which was introduced to the literature by the arbitrary way of Freud interpreted Narcissus myth. Based on an intense clinical case study, the aim of the current qualitative study is to elaborate on the contribution of narcissistic disturbances in difficulties of emotional regulation and self-destructive behavior in melancholic patients.
\end{abstract}

Methods: A female melancholic patient with severe self-destructive behavior and suicide attempts was interviewed through 72 sessions of the psychoanalytic therapeutic interview by a trained and supervised ego-psychology oriented therapist. The interviews were analyzed qualitatively via reflective analysis. A modified investigators triangulation method was used for testing and maximizing the validity and reliability of the interviews.

Results: The analysis of interviews revealed that the patient resorted to narcissistic defenses and mechanisms such as narcissistic identification and high ego ideal for dealing with frequent traumatic losses, and serious narcissistic assaults in her childhood. These narcissistic disturbances not only cussed melancholia by interfering and preventing the work of mourning but also lead to self-mutilation and self-destructive behavior.

Conclusion: Narcissistic disturbances in melancholia might give the upper hand to death drive in preventing the work of mourning as normal and necessary emotional regulation process after a traumatic object loss and attacks object relations through disobjectalizing function. We argued that considering Narcissus as a melancholic and his death as a suicidal act is more productive in elaborating the interaction of narcissism and death drive.

\section{* Corresponding Author:}

Bahram Ali Ghanbary Hashemabady, PhD

Address: Department of Psychology, Faculty of Education Sciences and Psychology, Ferdowsi University of Mashhad, Mashhad, Iran.

Tel: +98 (915) 3085887

E-mail: ghanbarih@um.ac.ir 


\section{Introduction}

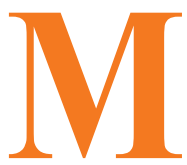

elancholia, a result of a failure in mourning for a traumatic object loss (Abbasi, 2016), is referred as chronic depression (Parker et al., 2010). It is a common illness worldwide, with $>300$ million people of all ages get affected (WHO, 2017) and is the third most prevalent mental disorder in Iran (Montazeri et al., 2013). Since it is one of the priority disorders covered by World Health Organization's (WHO) Mental Health Gap Action Program, it becomes an area of intense interest with time (Anastasopoulos, 2007).

Several studies demonstrated that narcissistic disturbances in childhood (Bartram, 2013; Clewell, 2004; Palacio Espasa, 2002; Pinheiro, Verztman, \& Viana, 2016), severe self-destructive behavior including suicide attempts (Corbett, 2009), and difficulties in emotional regulation (Joormann \& Stanton, 2016) are defining characteristic of this disorder. Montazeri et al. (2013) in a systematic review of the literature on this disorder reported that prevalence of the chronic depression varies from 5.63 to $73 \%$ in different sub-population of Iran. Most of the studies conducted in Iran were focused on the epidemiology, the prevalence of suicide, and testing the effectiveness of medication or different psychological interventions (Ebadi et al., 2017; Eskandari et al., 2014; Akbari, Taleb, \& Fathi-Ashtiani, 2015), rather than on the etiology of the disorder.

A Higher number of studies were conducted on the association of narcissistic disturbances and melancholia in other countries (Bartram, 2013; Corbett, 2009; Erkoreka \& Navarro, 2017; Tritt, Ryder, Ring, \& Pincus, 2010), none examined this issue qualitatively. Therefore, there is lack of qualitative research regarding the contribution of these disturbances on underlying dynamics of severe self-destructive behavior and difficulties in emotional regulation in these patients. These two gaps in literature represent a negligence of etiological factors and a theoretical ambiguity, which was introduced to the literature by the way Freud interpreted Narcissus myth. His arbitrary use of the myth in formulating narcissism led to the confusion about the interaction of narcissism and death drive. There is a lack of detailed investigations on its etiology and underlying dynamics on Iranian population. Therefore, this study (based on an intense case study) seeks to evaluate etiological point of view of melancholia to elaborate on how narcissistic disturbances contribute to difficulties in emotional regulation and self-destructive behavior in melancholia and suggest a revised interpretation of Narcissus myth.

However, myths and legends belong to the realm of literature, they have been interwoven with psychoanalysis (Berg, 2015; Honig, 2011) to such an extent that some authors believe that we need to recourse a literary work to shed light on clinical and theoretical problems (Mauss-Hanke, 2013).The way Freud used the Narcissus myth is a famous failed example in which downplay of the Narcissus death led to a non-comprehensive understanding of narcissism and obscures the concept's links to the final drive theory (Aversa, Baldieri, \& Marozza, 2004; Javanbakht, 2006).

At least four different versions of narcissus myth were recorded in which the legend's vitality is exhausted. All versions recount a specific pattern including spurn of lovers due to Narcissus self-absorption, a traumatic object loss and his failure in mourning the loss -as a regular process of the emotional regulation- which preceded his death by his self-destructive behavior. In most popular versions which Ovid recounted, Narcissus renounced his life and let himself die when he failed in his love with his self-image. In two of the four versions, a traumatic object loss (his twin sister or a man lover) and his inability to mourn the loss preceded a suicide attempt. In the third version, Narcissus killed himself with a dagger, and in the fourth version he just pined away from unrequited longings or drowned himself into the water (Coleman, 2007).

There is only one version that recounts Narcissus death as a homicide. Freud's attempts to denote the concept of narcissism were counted as a failed and entirely arbitrary by many authors (Aversa et al., 2004; Javanbakht, 2006) due to the exclusion of the most crucial part of the pattern which myth recounts. Narcissus's failure in regulating his emotions after the traumatic object loss, his self-destructive behavior and death (Aversa et al., 2004), which were surprisingly disregarded by Freud and many other authors, are the most striking themes of the myth, regardless of versions.

\section{Narcissism and its vicissitudes}

For Freud, narcissism was the result of an orientation of the drives towards the Ego and was defined as the libidinal complement of the self-preservative drives. Freud (Freud, 1914) redefined narcissism as a normal phase of sexual development. "Narcissism in this sense would not be a perversion, but the libidinal complement to the egoism of the instinct of self-preservation, a mea- 
sure which may justifiably be attributed to every living creature.” (Freud, 1914)

Formation of Ego ideal is a rescue operation for narcissism (Meissner, 2008; Smith, 1985; Tyson \& Tyson, 1984). Therefore, Ego ideal is an effort to restore the lost Shangri-La of the relations with the all-giving primary mother. In the process of forming this primary narcissism repository, the child seeks to recover his perfection in a disguised form of Ego ideal (Greenberg, 2016; Meissner, 2008). Green (2005) strongly believed that Freud failed to elaborate on other possibilities. Green (2005) noted that some mechanisms like the transformation of object libido into narcissistic libido named desexualization, which has been recognized narcissistic by Freud, could be presumed as death drive as described recently. His explicit mention of narcissistic libido opens the way for us to consider that at least some aspects of narcissism may follow along with the same lines of the anti-eroticism involved in the death drive, even if it is not accompanied by an open manifestation of self-destruction.

Green (2005) elaborated upon links of narcissism with final drive theory by two interrelated lines of thoughts. He emphasized that withdrawal of investment from objects is the most common way that death drive functions. Therefore, he gave voice to his own celebrated concept of disobjectalizing function, which is the essential purpose of death drive (Green, 1999b) and function against work of mourning as a process for regulation of emotions. He considered Ego ideal as a negative double of the ID which, as pressing as instinctual satisfaction obeying the pleasure principle, do not rest until it has achieved illusory emancipation from instinctual satisfaction.

It should also be noted that although the Ego ideal, regarding which ego evaluates itself and tries to achieve perfection (Dendy, 2010), the function of an ideal does not represent any consolation or compensation. At every place of instinctual satisfaction, it sets up its contrary. It accords an even more significant value to renunciation rather than satisfaction. Therefore, the ideal is the result of instinctual renunciation, which is an essential function of the death drive. Green dissected narcissism into three substructures, bodily, intellectual, and moral narcissism. The last structure is characterized by an economy that burdens ego by the victory of death drive and instinctual renunciation, which confers upon the Nirvana principle a relative preeminence over pleasure principle. Therefore, the subject will increasingly attempt to impoverish his object relations to reduce the ego to its vital object minimum, thus seeming triumphant. This attempt is continuously frustrated by the instincts, which require that satisfaction pass through an object. The only solution is a narcissistic cathexis of the subject, and according to Pasche, when the object is lost or disappoints, the result is depression (Green, 1986).

According to Freud (1914), narcissistic cathexis on the object and replacement of identification for object investment in melancholic patents give the chance to hate towards the lost object to attacks the ego- the substitute for the lost object-, abusing it, debasing it, making it suffers as it would do to a lost object. Freud implied (Freud, 1917; Freud, 1921) that the critical agency in mental apparatus causes self-destructive behavior and suicide attempts in melancholia (Hansell, 2000). Although he claimed that being hated or persecuted by Superego bring masochism into operation (Schafer, 1960). However, he was not convinced that superego could cause such massive amount of self-destruction, which leads to termination of mental apparatus latter (Green, 2005). Then, what else could cause such enormous self-destruction?

The solution to this theoretical dilemma lies somewhere in two crucial differentiations that need to be made. First, differentiation is between origins and functions of Superego and Ego ideal from the structural point of view and the second differentiation is between aggressive and destructive behavior. Freud provided an accurate reflection of Superego at the end of his work on studying primary masochism. It was then that Freud discovered libidinal co-excitation, and he did not cease to investigate the relations of pleasure and pain (Green, 2005). In the Economic Problem of Masochism (1924), which he published after authoring "Beyond the Pleasure Principle" (Freud, 1920) and conceptualization of death drive, Freud considered self-destructive tendency as a primary drive of the organism.

From 1942 onwards, masochism could not be reduced to a reversal of sadism, and masochism was reconsidered as the primary representative of the death drive. Green (2005) argued that it is indispensable to distinguish between aggressive and destructive behavior. Since the early days of psychoanalysis, aggressivity was linked to sadism and attached to the stages of the evolution of the libido, i.e. the anal-sadistic and oral-sadistic stages. The tortures and torments inflicted on the object are one of the expressions of a wish to master the purpose of ensuring one's absolute control and its domination in involving a jouissance that is only equaled in its inverted aspects, that is, in masochism (Green, 2005). Unlike sadism, destructive behavior does not only include unconscious jouissance, and it is beyond that, it is not easy to dissociate them. A sadist takes an unconscious pleasure 
in his object's masochism via identification. In destructive behavior, it is the narcissistic dimension that prevails the destructive subject wishes to destroy his object's narcissism. In other words, it is omnipotence, which is not necessarily accompanied by jouissance derived from sadism or masochism.

An unconscious sense of guilt is the primary pathology of Superego as heir to Oedipus complex when a conscious or unconscious satisfaction is driven by impulses or wishes associated with Oedipus complex. Therefore, death drive expression through Superego is limited to producing guilt feeling that Freud admitted his preference for the formula- a need for self-punishment. It is derived from sadomasochistic components of the sexual drive, therefore; it is not able to bring the destruction of mental apparatus.

Whereas, Ego ideal, known as heir to the primary narcissism, is a source of shame feeling (Meissner, 2008) and self-destructive tendency resulting from overwhelming shame feeling provides profound and widespread effects on entire mental apparatus (Green, 2005). Meissner confirmed that shame feeling is one of the emotions, the presence of which refers to the underlying deprivation or mortification related to narcissism and denial or failure of desires associated with narcissism (Meissner, 2008). Accordingly, it seems that what causes such massive and widespread self-destructive behaviors capable of demolishing narcissism of the Ego is the inability to regulate shame feeling derived from legitimate heir to primary narcissism, i.e. the Ego ideal.

Narcissism disturbances contribute to melancholia's massive self-destructive behavior in three different ways. First, regression to primary narcissism stage after traumatic object loss provides a fertile ground for replacement of object investment by narcissistic identification. Based on Freud's theory, this desexualization, i.e., withdrawal of libidinal investment from an object belongs to the culture of the death drive. Green called this process as disobjectalizing function, which is the most extreme way of preventing the work of mourning as a normal emotional regulation process after a traumatic object loss and at the service of death drive (Green, 1999a). Second, unattainable standards of Ego ideal in melancholic patients as heir to their injured narcissism in Freudian theory and as negative double of id in Green's view forced the subject to renounce object relations through encouraging renunciation of drive satisfaction by producing pride; and bringing about self-destructive behaviors via producing intense and overwhelming shame feeling when these patients encountered defects and failures. Third, these massive self-destructive behaviors in melancholic patients cannot be explained by the aggressive behavior of a harsh and punitive Superego, so contributions of narcissistic disturbances accompanied by the infantile omnipotence of infantile Ego ideal should be considered.

Narcissistic disturbances cause a lot of financial costs and deaths via high prevalence of melancholia in the Iranian population (Montazeri et al., 2013). Persian literature suffers from a conspicuous lack of etiological studies on how these disturbances contribute to the self-destructive behavior of melancholic patients. Therefore, the aim of this study was to evaluate the interaction of narcissistic disturbances with death drive and how it contributes to difficulties of emotional regulation and self-destructive behavior in melancholic patients in particular.

\section{Methods}

This qualitative study was designed based on a case study. A female melancholic patient, referred by a psychiatrist, with a diagnosis of melancholia with serious suicide attempts volunteered for participation. Clinical features reported by Fink and Taylor (2007) were used for differential diagnosis of Melancholia: An episode of illness with reduced functioning characterized by an unremitting mood of apprehension and gloom that compromises normal daily activities; Psychomotor disturbance as agitation, retardation, or both; Vegetative signs of poor sleep, appetite, libido, loss of weight, and interest; and Pre-occupation with suicide and self-destructive behavior.

Seventy-two intense psychoanalytic therapeutic interviews sessions were conducted by a trained and supervised ego-psychology oriented therapist, three times a week for six months (each session last 45 minutes). Whenever the patient or therapist missed a session, there was a compensatory session. The assessment was limited to qualitative interviews, and no quantitative questionnaires or scales were conducted. The therapeutic interviews were unstructured and based on free associations of the patient during the sessions and seven key aspects as described by Bachrach (2000). These key aspects were the individual case study, the open mode of interviewing, the interpretation of meaning, the temporal dimension, the human interaction, pathology as a topic of investigation, and the instigation of change.

Psychoanalytic therapeutic interviews were analyzed through reflective analysis, which is a popular type of analysis used in case study research and other qualitative research traditions (Dooley, 2002). Its use involves a decision by the researcher to rely on his or her intuition 
and personal judgment to analyze the data rather than on technical procedures involving explicit category classification systems (Dooley, 2002). A modified investigators triangulation method was used to improve analysis and understanding of the patient, testing and maximizing the validity and reliability of the study (Golafshani, 2003). In this method, the data collected from each of the three interview sessions were presented and discussed continuously with trained ego psychology oriented supervisors. The results were reported through reflective reporting, where the writer will use literary devices to bring the case alive for the reader and the strong presence of the researcher's voice is apparent (Gall, Gall, Borg, 2006).

\section{Results}

A reflective analysis of data collected from 72 psychoanalytic therapeutic interview sessions is summarized below.

Miss A was 21 years old when she sought treatment after breaking up with her boyfriend and was on medication for melancholia. The intense interviews revealed that she was unable to meaningfully connect to a man intimately and she has been subjected to some disorganizing experiences particularly traumatic separations and losses during her childhood. Her father left the family, and Miss A felt that her mother found it difficult to be warmth and emotionally connected. Miss A describes her mother depressed and inaccessible. Miss A struggled with spasms of intense and overwhelming feelings of abandonment, which prevails over her all the childhood memories. She could not admit and express any negative feelings of anger, rage, and hate. Whenever she was supposed to deal with these feelings, she defends against them through reaction formation and denial.

Her lifestyle suffered a remarkable turnaround following the traumatic break up with his boyfriend, which triggered severe symptoms including low mood, insomnia, loss of appetite, loss of weight, considerable difficulty in the regulation of negative feelings, and severe physical self-destructive behaviors including, practicing extreme physical exercises and following the hard and unbalanced diet. The way miss A provides unending and constant care for others was becoming more evident as we spoke and she has always shown considerable sensitivity to every situation that signifies loss, no matter loss of somebody or something.

Providing extreme support and care for others and making a hard effort to keep them satisfied (family members in particular) was the most striking feature in Miss A relations with others. Although Miss A experienced lots of distress, negligence, and an absence of interest by father, mother, and other family members, she usually took the role of an excellent mother in her relationships. She could not bear her anger, hatred, and rage towards her family and used to defend against these feeling through reaction formation, denials, splitting and whatever that helps her to keep these overwhelming emotions out of her consciousness.

As she began to talk in therapy, after a while, she demonstrated a stiff resistance. She kept self-analyzing her symptoms, behaviors, and dreams during the therapy sessions. Further reflection on resistance analysis would lead to a deeper understanding of dynamics associated with the narcissistic disturbances that are manifested through her inability to regulate her overwhelming emotions and self-destructive behaviors. She was able, over time, to see her self-analysis as an effort to take care of a therapist and a great wish to be neglected by the therapist. She was convinced deeply that she should endeavor to be a perfect and flawless patient and she did her best not to disappoint the therapist. Otherwise, she would feel that there was something wrong about her and felt ashamed of herself.

It is interesting to note that she did not reveal any sign of adverse transference feeling or reaction until that time. As she continued to talk in therapy, she gradually became able to see her hostility and anger towards her family members, particularly her mother and overcome her difficulty in expressing them in therapy. After a while hostility towards therapist and passive suicidal thoughts came up in the sessions, respectively. Therapist felt scared that she might harm him or might commit suicide because he heard her identification with her absent and emotionally disconnected parent and also a wish to worry and scare him. He felt confused and considering in his mind "how should I deal with her?", "what would happen to me if she committed suicide?"

Sometimes, his confusion turned into anxiety, anger or a tendency to drop the patient. While trying to find out the reasons behind patient's negative transferential feeling and reaction, the therapist asked himself: "since she started treatment, many improvements have been achieved. She had gone off the medication, was employed, financially independent, and recovering from insomnia. So, why is she still angry at me (the therapist)? Why does she try to scare me?". However, the therapist was acutely aware of negative transference reactions, the therapeutic nature of such feeling expression, and the fact that such responses were in the right place (analytic space). On the other hand, it cannot be denied that con- 
taining her hostility was a little hard until in the process of his analysis and sessions of treatment supervision. Therapist found out that he was unconsciously afraid of such feelings and considered them destructive and dangerous like the patient. Gradually, she was able to see the hostility in what she was doing with a therapist. Therapist worry about taking care of her, as though there was no other way she could or would get such care. It has been elaborated -after working through these mattersthat the extreme support and care which she provides for others were rooted in her inability to express her anger and hatred towards others due to her fear to lose them. Although the patient could not bear the loss of significant objects, the loss was being repeated compulsively.

After a while, her attempts for self-analyzing were interpreted in another line of thought based on her narcissistic disturbances. She was defending herself from therapist recognition of her defects and disabilities through self-analyzing herself. Moreover, the self-analysis was the way Miss A expressed her anger towards the therapist. On the one hand, she tried to neglect therapist, but on the other hand, she raised an unconscious expectation to be ignored by the therapist as if she stated: "You should also neglect me in the same way my maternal object did to me." In fact, the patient sought to repeat the familiar neglectful atmosphere of her family relationship in transference. Patient's compulsion to repeat for traumatic separation and loss can be inferred from therapist's counter transferences which include: an inclination to drop her and giving her wild interpretation while dealing with patient's negative transference.

In summary, the reflective analysis of interviews revealed that the patient resorted to narcissistic defenses and mechanism such as narcissistic identification and high ego ideal for dealing with frequent traumatic losses and intense narcissistic assaults in her childhood. These narcissistic disturbances may not only interfere and prevent the work of mourning which cussed melancholia and but also leads to her self-mutilation and self-destructive behavior.

\section{Discussion}

Freud utilized narcissuses myth to elaborate on narcissism. He failed because he ignored the destructive tendency in narcissus character and overemphasized on his self-absorption. Based on a clinical case, Freud's theory of narcissism and contribution of Green on expressions of the death drive, this study seeks to explore vicissitudes of narcissism and how its disturbances lead to emotion regulation difficulties and destructive behaviors.
Miss A had suffered from a range of traumas in her intimate relationships including a feeling of abandonment, loss of important objects, being neglected and humiliated in her childhood. The more she became able to contain and express her negative feeling, particularly her hostility and anger in therapy without being ashamed of herself, the less she felt sad and intended to self-destructive behaviors and could engage in meaningful relationships. The way Miss A takes a protective role in her relations (particularly in transference) could be elaborated by the self-disappearance mechanism.

Green (2005) described that when the separation from mother is traumatic and characterized by abandonment, the child would experience his mother inaccessible. The mother, who is 'elsewhere,' progressively becomes for the child the object of an ambivalent, perpetually demanding fixation, without the feeling of passionate love, being given any recognition. Consequently, an internal reorganization occurs, in which the subject who has experienced distress, negligence, and an absence of interest consider his mother as a child whom he has to take care. It seems that having an absent mother (or even family), who was not only unable to take care of her child, but also needed full attention, sympathy, and care like a child, has left permanent narcissistic injuries and vulnerabilities, which resulted in her unattainable Ego ideal that forces her to be perfect and flawless. A wider range of unattainable and high-level ideals including being a perfect patient for the therapist, not having feelings such as anger, hatred, and rage, and even seeking situation without frustration have been unfolded over the course of treatment. Furthermore, she was not able to tolerate recognition of any needs to others and even objects.

Being in need of a tissue paper to wipe her tears or even being in need of therapy were the most intense anger triggers for Miss A that were followed by overwhelming feelings of inferiority, rage, sadness, and harsh self-criticism and sometimes psychical self-destructive behaviors. These unattainable ideals always made her feel disable, defective, and ashamed of herself and made her doubt about her goodness. She could not recognize, admit and regulate these feelings, so they were always followed by a robust self-destructive tendency and behavior including self-inflicted physical wounds and psychical self-abasement.

Green's contention is that the jouissance derived from sadistic impulses of Superego cannot be brought about such a violent self-destructive behavior (Green, 1983). According to Green, failure in regulating the shame feeling derived from failures of Ego ideal can merely be 
responsible for such tendency towards self-destructive behaviors. In other words, unattainable Ego ideal of the patient provides a fertile ground for producing unbearable shame feeling and operation of disobjectalizing function of death drive, which prevents normal mourning, brings self-critical symptoms, physical, psychical self-destructive behaviors and withdrawal of object relations into operation. Green strongly emphasized that demolition of Ego is alleged to a particular pathology in the structure of narcissism (Green, 2005). He describes the fusion of death drive with narcissism in proper narcissism configuration (Green, 1986) in which attachment to infantile megalomania and being in debt of Ego ideal is always included as defining characteristics. The result of this collaboration is not a sense of guilt; however, it is a kind of shame feeling due to the recognition of any imperfection or defects. In such circumstances, the death drive, seeking renunciation of instinctual satisfaction and sacrifice of pleasure, prevail over life drive, seeking instinctual and pleasure.

Those mentioned above confer upon Nirvana principle (the lowering of tension to a zero level) a relative preeminence over pleasure principle in a moral narcissist (Green, 1986). From our point of view, self-hatred and self-destructive behaviors that Miss A used to inflict to herself can be explained by her inability to regulate unbearable shame feeling followed by failures of unattainable Ego ideal (Simpson, 2014). Given the fact that the object whose shadow was cast over the patient's Ego is probably the image of an absent mother who was full of defects and flaws, such self- and other- destructive tendency cannot be far-fetched.

Although according to the Freud's theory, Narcissus embraces essential preconditions and consequences of melancholia including narcissistic object choice, object loss, narcissistic identification, inability to mourn and self-destructive behavior. Freudian view missed function of ideal and impacts of the death drive through a disobjectalizing task which could attack not only object relation but also all its substitutes mainly the Ego via withdrawal of investment (Green, 1999b).

It can be deduced that Narcissus suffered from melancholia and committed suicide. He was traumatized by the loss of his Ego ideal and could not regulate the following shame and was forced to renounce his narcissism once again by killing himself. He withdraws any investment in objects and eventually abandons his Ego. Therefore, as it was quoted, he committed suicide at the end of the myth. This self-destructive behavior has been brought into operation by Narcissus's inability to regulate shame feeling due to his failure obtaining the ideals of his Ego ideal (to be loved by others) and disobjectalizing function of the death drive.

Freudian interpretation of the myth only emphasizes self-absorption of narcissus and is ignorant of his difficulty in emotion regulation and self-destructive tendency or even his death. One of the primary reasons for exclusion of narcissus death in Freudian interpretation was vague relations between narcissism and final drive theory at that time, which led to a non-comprehensive understanding of the concept of narcissism and kept connections between narcissism and death drive as a mystery. But through a broader conceptualization of narcissism and the ways death drive impacts on object relations provided by Green; we can achieve a complete interpretation of the myth. The disobjectalizing function of death drive as result of the role of ideals and particular narcissistic pathology, which is called moral narcissism, is involved in the ultimate fate of Narcissus. The centrality of drives and their satisfaction in Freud's theory would be another reason for Freud's inability to include the final part of the myth in his conceptualization of narcissism. But Green's emphasis on the importance of the object, even in the appearance of drives (Green, 1999b) enables us to take renunciation of object relations, which led to narcissus death at the end of the myth into considerations.

Authors conclude that narcissistic disturbances can result in death drive predominance in melancholia, which prevents the mourning as a normal and necessary emotion regulation process after a traumatic object loss and attacks object relations through disobjectalizing function. We argue that narcissistic identification and high ego ideal that the melancholic patients utilize to deal with traumatic losses and serious narcissistic assaults provide the fertile ground for the most common way that death drive functions, i.e., withdrawal of investment from objects.

Our study is limited by lack of qualitative and quantitative background in both Persian and non-Persian literature; therefore, it was difficult to interpret our result through a rich body of research. This study was an initial effort in elaborating on melancholic patients and their difficulties in emotional regulation and severe self-destructive behavior from the etiological point of view in Iran. Therefore, we had to limit the case study to the contribution of narcissistic disturbances, and focus on one case to more precision; we suggest to enthusiast researchers to conduct qualitative research on etiology of this prevalent and severe disorder. Psychotherapies that address narcissistic disturbances and difficulties in emotional regulation should be included in the treatment of melancholic 
or chronic depressed patients because if they could recover their narcissistic injuries and overcome problems in emotional control, they might be able to mourn their losses and return to a normal life as it happened to the patient participated in current study.

\section{Acknowledgments}

We would like to express warm thanks to Dr. Fred Busch and Mr. Ghorkhanechi who were the first readers and whose valuable comments helped us greatly. We also owe thanks to Mr. Dehghan, Hashemiyan, and Hanaei for their help, support and inspiration. We also owe thanks to Mohsen Dehghan, Sepehr Hashemiyan, and Hooman Hanaei for their help, support and inspiration. This research received no specific grant from any funding agency and is a part of the $\mathrm{PhD}$ dissertation of the first author in the Department of Psychology, Faculty of Education Sciences and Psychology, Ferdowsi University of Mashhad.

\section{Conflict of Interest}

The authors have no conflicts of interest to declare.

\section{References}

Abbasi, A. (2016). The Therapist in Mourning: From the Faraway Nearby. Edited by Anne J. Adelman and Kerry L. Malawista. The Psychoanalytic Quarterly, 85(1), 234-239. doi: 10.1002/psaq.12069

Akbari, F., Taleb, M., \& Fathi-Ashtiani, A. (2015). [The effectiveness of transcranial Direct Current Stimulation of the brain (tDCS) on reducing depressive symptoms among people with Depressive Disorder (Persian)]. Journal of Behavioral Sciences, 9(1), 95-101.

Anastasopoulos, D. (2007). The narcissism of depression or the depression of narcissism and adolescence. Journal of Child Psychotherapy, 33(3), 345-362. doi: 10.1080/00754170701667197

Aversa, G. L., Baldieri, V., \& Marozza, M. I. (2004). The mythic function of narcissism. Journal of Analytical Psychology, 49(4), 553-568. doi: 10.1111/j.0021-8774.2004.00483.x

Bachrach, H. M. (2000). Notes on psychoanalysis, psychotherapy and methodology. Psychoanalytic Inquiry, 20(4), 541-555. doi: 10.1080/07351692009348906

Bartram, P. (2013). Melancholia, mourning, love: Transforming the melancholic response to disability through psychotherapy. British Journal of Psychotherapy, 29(2), 168-181. doi 10.1111/bjp.12002

Berg, M. (2015). Myth, Literature, and the unconscious by Burnett, Leon, Bahun, Sanja, \& Main, Roderick (Book re- view). Journal of Analytical Psychology, 60(2), 157-299. doi 10.1111/1468-5922.12148_2

Burnett, L., Bahun, S., Main, R. (2015). Myth, Literature, and the Unconscious. London: Karnac Books.

Clewell, T. (2004). Mourning beyond melancholia: Freud's psychoanalysis of loss. Journal of the American Psychoanalytic Association, 52(1), 43-67. doi: 10.1177/00030651040520010601

Coleman, J. A. (2007). The dictionary of mythology an A-Z of themes, legends and heros. San Francisco: Capella.

Corbett, K. (2009). Melancholia and the violent regulation of gender variance: reply to commentaries. Psychoanalytic Dialogues, 19(4), 385-392. doi: 10.1080/10481880903088500

Dendy, E. B. (2010). Inherent Contradictions in the Ego Ideal. Psychoanalytic Quarterly, 79(4), 991-1023. doi: 10.1002/j.21674086.2010.tb00474.x

Dooley, L. M. (2002). Case study research and theory building. Advances in Developing Human Resources, 4(3), 335-354. doi: $10.1177 / 1523422302043007$

Ebadi, M., Hosseini, F., Pahlevan, F., Esmaeil zade, A. M. Farhadi, V., \& Asghari, R. (2017). [The effectiveness of transcranial Direct Current Stimulation of the brain (tDCS) on active memory of people with major depression (Persian)]. Arak Medical University Journal, 20(5), 38-47.

Erkoreka, L., \& Navarro, B. (2017). Vulnerable narcissism is associated with severity of depressive symptoms in dysthymic patients. Psychiatry Research, 257, 265-269. doi: 10.1016/j.psychres.2017.07.061

Eskandari, Z., Taremian, F., Nazari, M. A., Bakhtiyari, M., Momtazi, S., \& Rezaei, M. (2014). [Effectiveness of neurofeedback treatment on the severity of major depression symptoms (Persian)]. Journal of Zanjan University of Medical Sciences $\mathcal{E}$ Health Services, 22(92), 86-95.

Fink, M., \& Taylor, M. A. (2007). Resurrecting melancholia. Acta Psychiatrica Scandinavica, 115(s433), 14-20. doi: 10.1111/j.16000447.2007.00958.x

Freud, S. (1914). On narcissism: An introduction. In J. Strachey (Ed.), The Standard Edition of the Complete Psychological Works of Sigmund Freud, Volume XIV (pp. 67-102). London: Hogarth Press.

Freud, S. (1917). Mourning and melancholia (Vol. XIV). [J. Strachey English Trans]. London: Hogarth Press.

Freud, S. (1920). Beyond the pleasure principle. In J. Strachey (Ed.), The Standard Edition of the Complete Psychological Works of Sigmund Freud, Volume XIV (pp. 1-64). London: Hogarth Press.

Freud, S. (1921). Group psychology and the analysis of the ego. The standard edition of the complete psychological works of Sigmund Freud, Volume XVIII (1920-1922). London: Hogarth Press.

Freud, S. (1924). The economic problem of Masochism. In J. Strachey (Ed.), The Standard Edition of the Complete Psychological Works of Sigmund Freud, Volume XIV (pp. 155-170). London: Hogarth Press.

Gall, M. D., Gall, J. P., Borg, W. R. (2006). Educational research: An introduction. London: Pearson. 
Golafshani, N. (2003). Understanding Reliability and Validity in Qualitative Research. The Qualitative Report, 8(4), 597-606.

Green, A. (1986). Moral narcissism. International Journal of Psychoanalytic Psychotherapy, 8, 243-269.

Green, A. (1983). [Narcissism of life, Narcissism of death (French)]. Paris: Editions de Minuit.

Green, A. (1999a). The fabric of affect in the psychoanalytic discourse. London: Routledge.

Green, A. (1999b). The work of the negative. London: Free Association Books.

Green, A. (2005). Key ideas for a contemporary psychoanalysis: Misrecognition and recognition of the unconscious. London: Routledge.

Greenberg, D. E. (2016). A review of traumatic narcissism: relational systems of subjugation. Contemporary Psychoanalysis, 52(1), 130-143. doi: 10.1080/00107530.2016.1149392

Hansell, J. H. (2000). Mourning and melancholia in superego development and resistance to change. Journal of Clinical Psychoanalysis, 9(2), 255-277.

Honig, R. G. (2011). Memory, myth, and seduction: unconscious fantasy and the interpretive process. Journal of the American Psychoanalytic Association, 59(6), 1255-60. doi: $10.1177 / 0003065111427160$

Javanbakht, A. (2006). Was the myth of narcissus misinterpreted by Freud? Narcissus, a model for schizoid-histrionic, not narcissistic, personality disorderarash javanbakht. The American Journal of Psychoanalysis, 66(1), 63-71. doi: 10.1007/s11231-0059003-1

Joormann, J., \& Stanton, C. H. (2016). Examining emotion regulation in depression: A review and future directions. Behaviour Research and Therapy, 86, 35-49. doi: 10.1016/j.brat.2016.07.007

Mauss-Hanke, A. (2013). Psychoanalytic considerations about theanti-oedipal conditionin Heinrich von Kleist'sPenthesileaand in the analysis of Miss M1. The International Journal of Psychoanalysis, 94(3), 477-499. doi: 10.1111/j.1745-8315.2012.00661.x

Meissner, W. W. (2008). Narcissism as motive. Psychoanalytic Quarterly, LXXVII(3), 755-798.

Montazeri, A., Mosavi, S. J., Omodvari, S., Tavoosi, M., Hashemi, A., \& Rostami, T. (2013). [Depression in Iran: a systematic review of the literature (2000-2010) (Persian)]. Payesh, 12(6), $567-594$

Palacio Espasa, F. (2002). Considerations on depressive conflict and its different levels of intensity: Implications for technique. The International Journal of Psychoanalysis, 83(4), 825-36. doi: 10.1516/15hh-h25e-jbvx-9par

Parker, G., Fletcher, K., Barrett, M., Synnott, H., Breakspear, M., Rees, A. M., et al. (2010). Inching toward Bethlehem: Mapping melancholia. Journal of Affective Disorders, 123(1-3), 291-98. doi: 10.1016/j.jad.2009.10.001

Pinheiro, T., Verztman, J., \& Viana, D. (2016). Melancholia, Narcissism and Depression. The American Journal of Psychoanalysis, 76(3), 281-94. doi: 10.1057/s11231-016-9047-4
Schafer, R. (1960). The loving and beloved superego in Freud's structural theory. The Psychoanalytic Study of the Child, 15(1), 163-88. doi: 10.1080/00797308.1960.11822573

Simpson, D. (2014). Someconsequences of being the wrong child: effects of the intergenerational transmission of an ideal-ego. British Journal of Psychotherapy, 30(2), 181-196. doi: 10.1111/bjp.12079

Smith, D. L. (1985). Freud's developmental approach to narcissism: A concise review. International Journal of Psycho-Analysis, 66(4), 489-497.

Tritt, S. M., Ryder, A. G., Ring, A. J., \& Pincus, A. L. (2010). Pathological narcissism and the depressive temperament. Journal of Affective Disorders, 122(3), 280-284. doi: 10.1016/j. jad.2009.09.006

Tyson, P., \& Tyson, R. L. (1984). Narcissism and Superego Development. Journal of the American Psychoanalytic Association, 32(1), 75-98. doi: 10.1177/000306518403200106

WHO. (2017). Depression. Retrieved from http://www.who.int/ campaigns/world-health-day/2017/en/ 
